\title{
A Principles-based Response to the Proposed Reform of the Governance Structure for Listing Regulation in Hong Kong
}

\section{AIIFL Working Paper No. 19}

November 2016

Asian Institute of International Financial Law

Faculty of Law

The University of Hong Kong

www.AIIFL.com

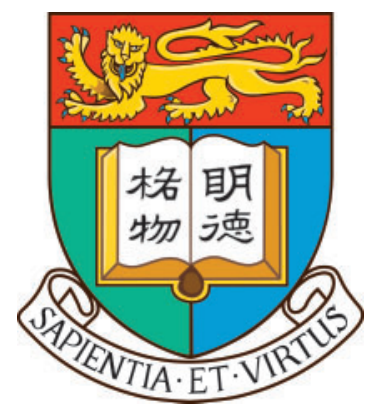

(C) November 2016 the authors. All rights reserved. Short text extracts may be quoted without explicit permission provided that full credit including the "C)" notice is given to the source. 


\title{
A principles-based response to the proposed reform of the governance structure for listing regulation in Hong Kong
}

\author{
Syren Johnstone*, Nigel Davis ${ }^{* *} \&$ Douglas W. Arner ${ }^{* * *}$ \\ Asian Institute of International Financial Law \\ University of Hong Kong
}

\begin{abstract}
$^{+}$
The June 2016 joint consultation on listing regulation arises out of a renewed concern to ensure the Hong Kong market remains fit for purpose in meeting current and emergent challenges and demands. This paper undertakes an analysis of the consultation applying a law and principles based approach. This approach requires the listing regime to be suitable not only in view of market conditions but also in view of internationally accepted practices and standards concerning regulatory oversight. While it is recognized that regulatory evolution requires progressive innovation, the two new SEHK sub-committees envisaged by the joint consultation give rise to several areas of concern. The reasons for implementing the changes proposed are not well explained in the consultation and no clear case is presented as to why the sub-committee structure would provide improvements. Putting the SFC into a frontline decision-making role is problematic under the current statutory framework, and is not necessarily a forward moving step toward a system of statutory listing regulation. It implements changes that bypass legislative intent and renders certain statutory laws meaningless, it may subject the SFC to corporate laws that would impact on its ability to act as an independent regulator, and it would diminish regulatory accountability and clarity. The risk that the changes could be regarded as legislation by regulation would weaken, not strengthen, the SFC's regulatory mandate over public listings. These problems run counter to the intent of the Proposal to improve listing regulation and carry the risk that Hong Kong's governance of listings, particularly the role of the statutory regulator in it, would be at odds with international best practices. The conclusion of this paper is that progressing with the sub-committee proposal would not be a positive development unless and until the issues identified in this paper are properly addressed and resolved. It is suggested that a more holistic view of market development needs to be adopted that extends beyond the decision making mechanisms of the dual filing regime and identifies more precisely the specific issues that are problematic. Doing so would permit more targeted and sustainable oversight mechanisms to be developed.
\end{abstract}

\footnotetext{
* Adjunct Associate Professor, Faculty of Law, University of Hong Kong; Fellow, Asian Institute of International Financial Law; Solicitor (England \& Wales, Hong Kong, nonpractising).

Principal Lecturer, Department of Professional Legal Education; Deputy Director, Asian Institute of International Financial Law; Former Member of the Listing Committee (2010 to 2014).

*** Professor of Law, Co-Director, Duke-HKU Asia America Institute in Transnational Law, Co-Founder, Asian Institute of International Financial Law, and Director, LLM in Compliance and Regulation, University of Hong Kong.

+ The author's acknowledge the financial support provided by the RGC Theme-based Research Scheme Project: "Enhancing Hong Kong's Future as a Leading International Financial Centre".
} 


\section{CONTENTS}

Executive summary

1. Approach

2. Background and evolution

3. Current structure

4. Overview of the consultation paper Proposal

5. Observations

6. Considerations

6.1 Regulatory architecture and legislative considerations 6.1.1 Architecture

6.1.2 Legislative intent

6.1.3 Statutory checks and balances - SFC

6.1.4 Statutory checks and balances - SEHK

6.1.5 Legislation by regulation

6.2 Corporate law

6.2.1. SEHK's corporate governance

6.2.2 Shadow director

6.3 Principles of securities regulation

6.3.1 Accountability

6.3.2 Regulatory clarity

6.3.3 Conflicts

7. Perspectives

7.1 Current communication arrangements

7.2 What problem?

7.3 Listing authority

7.4 SFC's extant powers

8. Conclusions 


\section{Executive summary}

This paper is a response and submission to the proposals made by the Securities and Futures Commission ("SFC") and The Stock Exchange of Hong Kong Limited ("SEHK") in their Joint Consultation Paper - Proposed Enhancements to The Stock Exchange of Hong Kong Limited's Decision-making and Governance Structure for Listing Regulation issued in June 2016 (the "Proposal").

An analysis of the Proposal is undertaken based on the law and well-established principles of securities regulation. As such, it is architecture oriented rather than results oriented. It is premised on the proposition that a sound regulatory structure is the foundation to continued successful development of the market. This encompasses efficiency, accountability, transparency and predictability in listing regulation.

The development of a regulatory framework should not be frozen in time - it should evolve so as to remain fit for purpose in view of current and emergent market conditions. Hong Kong's regulatory architecture has evolved in significant ways since the establishment of the SFC in 1989. Many of these developments have been in response to the changing profile of the Hong Kong market, including its internationalization, its overall size in world terms, and Hong Kong's special position in relation to the rapid emergence of Chinese business enterprises since the early 1990s. This has resulted in some principles being tested against practices in other markets (such as the one share one vote principle and weighted voting rights) while others have been reinforced by both established and developing international standards (such as the nature and scope of the regulatory mandate). Identifying which aspects of Hong Kong's architecture comprise essential foundations of the system and which are in need of modernization is not a straightforward matter. Any development must of course occur within the wider framework of Hong Kong's legal system.

While the Proposal is positioned within the framework of a progressive approach to regulatory oversight of a changing marketplace, the analysis in this paper indicates a number of problematic issues that risk confusing or weakening the regulatory mandate of the SFC in relation to the admission and trading of publicly listed securities. As such, aspects of the Proposal run counter to its aim of improving listing regulation in Hong Kong and could instead work to stultify listing regulation development and/or send it backwards. Many of the issues arise out of the fact that the newly proposed Listing Policy Committee ("LPC") and Listing Regulatory Committee ("LRC") are both sub-committees of the SEHK in which the SFC has both "Negative Control" and "Looming Control" (as defined in section 5 of this paper).

Issues of concern can be grouped into three main areas.

First, as regards regulatory architecture and legislative considerations.

If the Proposal were implemented, the legislative intent of certain provisions of statutory law may be bypassed and/or rendered meaningless. This includes checks and balances important to the integrity of the regulatory governance of listing matters.

The reporting obligations of the SEHK to the SFC in respect of proposed rule changes would be altered significantly such that the proposer-challenger relationship between the two bodies, each with overlapping but independent powers, embedded in the current regulatory architecture would be collapsed into a single-body sub-committee. 
Similarly, the ability of the SFC to independently undertake its statutory supervisory role of the SEHK including its decision-making processes becomes impaired by the SFC's participation in the SEHK sub-committees.

Where a listing applicant seeks approval for listing, if the matter does not go before the LRC, any exercise of the SFC's powers to object to it is a public action subject to review by the Securities and Futures Appeals Tribunal ("SFAT"). In contrast, if the matter were to go before the LRC, the SFC could use its voting power to achieve the same result - an objection to the listing - however, here its power would not be subject to review by the SFAT. Nor would there be any transparency imposed on the SFC in terms of the reasons for the rejection as the decision would, despite the SFC's influence on the LRC, technically be the decision of the SEHK not the SFC. Placing the SFC in a position of being able to exercise a public power through other means that provide for no path for appeal or review would place Hong Kong significantly out of step with all major financial marketplaces. This is because it is a fundamental premise of modern legal systems that where statutory power is given to a body it must be accountable in its exercise of the power - the legitimacy of the SFC's regulatory mandate depends on this.

The composition of the LPC and LRC are notionally equally weighted between the SEHK and the SFC, giving them both negative control of the sub-committees, However, the apparent equality arising upon neither party having absolute control is subject to the looming shadow of the SFC's ultimate powers under the Securities and Futures Ordinance ("SFO") ${ }^{1}$ and the Securities and Futures (Stock Market Listing) Rules ${ }^{2}$ ("SMLR") to direct, impose or reject any matter that the LPC or LRC might recommend or approve (see the definitions of Negative Control and Looming Control in section 5). This effectively moves the SFC's position from goalkeeper into the playing field and so enables the SFC to influence listing decisions at an earlier stage of the process. As such, the Proposal represents a repositioning of the SFC's powers from being a reserve power to block undesirable listings and to this extent is inconsistent with the powers given to it by the legislature at the time the dual filing regime was introduced.

To the extent the Proposal could amount to the bypassing of legislative intent by regulators overwriting, rewriting or reinterpreting what statutory law provides for, this could be regarded as legislation by regulation that brings into question whether the regulators would, under the arrangements contemplated by the Proposal, be acting ultra vires the mandate the legislature has entrusted to them.

Second, as regards considerations arising out of corporate law.

As both the LPC and LRC are sub-committees of the SEHK, the duties of the directors of the directors of the SEHK board need to be considered. While they can delegate certain functions to the sub-committees, they cannot abdicate their overall responsibility to supervise them. Neither new listing rules nor memoranda of understanding with the SFC are capable of altering this point of law. This will entail the SEHK board supervising, inter alia, the CEO and other executives of the SFC.

A further, and related, problem arises out of the effective powers of control the SFC is capable of exercising in the LPC and LRC. This reality gives rise to the risk that the SFC could, via de facto control of these sub-committees, come to be

\footnotetext{
${ }^{1}$ Cap. 571

${ }^{2}$ Cap. 571V
} 
regarded as a shadow director of the SEHK. Certainly, it is the case, if not the clear intention, that the SFC exercising its voice through the LPC and LRC will guide and control the SEHK's acts in relation to listing regulation. If that is the case, then the SFC would need to consider its fiduciary duties to the SEHK as well as its duties under the Companies Ordinance. ${ }^{3}$

Both of the above matters give rise to arrangements perverse to the independence of the SFC and the regulatory hierarchy contemplated by the legislature as well as what is widely understood and expected in the market. It would also put Hong Kong significantly out of step with international practices.

Third, as regards considerations relating to principles of securities regulation.

The legitimacy of the SFC in undertaking its regulatory mandate requires that it be subject to an appropriate framework of transparency and accountability. This is reflected, internationally, in IOSCO's ${ }^{4}$ "Objectives and Principles of Securities Regulation"5 (the "IOSCO Principles"), which require regulatory bodies to be publicly accountable. The Proposal does address transparency and accountability, but only within a narrow inter-regulator framework, i.e. as between the SFC and the SEHK. This falls short of the public requirement, it being noted that the problems identified in this paper give rise to concerns when considering the use and exercise of the SFC's statutory powers. It is inappropriate that a statutory regulator may optionally shift between public powers that are subject to a public accountability framework and others that are not.

The twin problems attendant on this is a deterioration of regulatory clarity, and ingresses on the ability of the SFC to continue to act independently.

As to the potential deterioration of clarity, it is reasonable to query whether it is realistically possible for either sub-committee to approve or reject a matter and the SFC to hold a different view such that it would be obliged to consider its statutory functions, powers and duties? It is posited that the role of the SFC in Hong Kong's architecture demands that an affirmative answer is capable of being given, yet this is uncertain since otherwise this would appear to run counter to the intended benefits of the "streamlined" approach.

The problem of independence, which goes to the essence of the SFC's creation in 1989 , arises as a result of actual, potential, or perceived conflicts that might come about by virtue of the SFC's senior officers participating in both subcommittees of another company (the SEHK) while also being subject to regulatory duties. Decisions of the LRC may at a later time come to require the further scrutiny of the SFC, for example, where the LRC has approved a listing application but subsequently, as an issuer, the company is suspected of some form of wrongdoing. One item that highlights the conflict issue is the secrecy provisions of the SFO, which would not prohibit an SFC officer from performing their regulatory functions within the SFC yet would prohibit them from participating in a sub-committee concerning a company of interest. Moreover, the participation of SFC officers in SEHK sub-committees that are subject to statutory supervision, monitoring and regulation by the SFC creates an actual conflict where subordinate staff are involved as regulatory supervisor. Even if the conflict is managed through staff changes, a perceived institutional conflict remains - it being noted that the legislature has not contemplated the ramifications of SFC

\footnotetext{
3 Cap. 622

${ }^{4}$ International Organization of Securities Commissions.

5 May 2003
} 
participation in front line decision making within the SEHK's decision making organs.

The three areas of concern summarized above are discussed in more detail in section 6 below. The issues in large part arise as a result of the SFC's involvement in the sub-committee of another corporate body, and its stated intent to move from goalkeeper into the playing field. Putting aside these specific issues, none of which have been identified or addressed in the Proposal, there is another important matter to consider.

This evolution of regulatory reform is normally framed in debates that centre on a clearly proposed justification for change. Certain difficulties in the market are in general well known, such as the exchange's conflict of interest as commercial entity and frontline regulator, the suitability of new listing applicants, backdoor listings, the granting of waivers by the SEHK, the behaviour of directors and controlling shareholders, market manipulation, and so on. Some of these have been concerns in the market at least since the Hay Davison Report in $1988 .^{6}$ The Proposal has been welcomed by many as an attempt to address the SEHK's perceived failure to tackle these longstanding problems. However, although the SEHK is described as the frontline regulator of listed companies under the current regulatory structure, the scope of its authority is in fact limited insofar as it is subject to the SFC's regulatory oversight. The Listing Rules and listing policy are ultimately subject to the approval of the SFC. Real power, in the ultimate sense, already rests with the SFC.

In contrast, the Proposal fails to identify the specific problems it is intended to address and why or how the LPC and LRC are the solutions. The stated objectives of greater coordination and streamlining remain similarly ungrounded by not identifying in what ways the current system, which already incorporates bodies that coordinate between the SEHK and SFC, fails. This leaves the Proposal appearing to be presented as a panacea for all ills in the market, which is unacceptably vague.

Identifying specific problems allows for specific solutions. The SFC does have meaningful and effective powers under the current system. While it does have a range of enforcement powers available to it, enforcement is not a substitute for effective gatekeeping that ensures the quality of listed issuers. The SFC also has important statutory powers it may exercise that go beyond those given to it under the dual filing regime to object to or impose conditions on new listing applications. It has the power to direct the SEHK to make listing rules and to create subsidiary legislation. While such powers could in theory be used to give the SFC a decision making role that achieves or goes beyond that envisaged under the sub-committee structure, used judiciously, such powers can also be used in targeted and specific ways. For example, if the SFC wished to take issue with the SEHK's granting of waivers as a matter pertaining to the interests of investors, it would be well within the existing powers of the SFC to seek to require that waivers are only granted with their prior approval. This would represent a targeted and technical resolution within the existing regulatory framework and for this reason it would also be likely met with significantly less resistance.

Some view the Proposal as a halfway step toward the listing authority model employed in the UK, citing regulation by a statutory body an approach being taken in other international markets. However, the Proposal is replete with

\footnotetext{
6 "The operation and regulation of the Hong Kong Securities Industry", Report of the Securities Review Committee, May 1988.
} 
serious problems, does not represent the development of a publicly accountable and transparent statutory body that regulates listing matters and, consequently, may actually work to stymie proper development and lead to distractions and revisionism.

The primary conclusion of this paper is that implementation of the Proposal would create dangerous legal and regulatory conundrums within what is currently a relatively clear architecture, while at the same being unclear as to why the LPC and LRC would bring any benefits over and above the current arrangements. Failing to address these problems may cause the SFC's continued standing as an independent regulator acting intra vires in relation to listing regulation to be called into question. Such an outcome would be profoundly undesirable. It is suggested that a more holistic view of market development needs to be adopted that extends beyond the decision making mechanisms of the dual filing regime and identifies more precisely the specific issues that are problematic. Doing so would permit more targeted and sustainable oversight mechanisms to be developed. 


\section{Approach}

Many opinions publicly expressed to date do little to advance a rational assessment of the Proposal, often revealing little or no traction with its substance or appreciation of the current regulatory architecture of Hong Kong and its evolution. Others are patella-like reflexes from stakeholders that tend to resist change. Still others, whether for or against the Proposal, amount to little more than an argumentum ad verecundiam. ${ }^{7}$ Opinions and views that comprise an argument from consequences unsubstantiated by evidence ${ }^{8}$ do little to advance a reasoned dialogue. Fortunately, a number of submissions do respond to the detail of the Proposal and are concerned with expounding a considered analysis.

The approach undertaken in this paper is based on a law and principles-based understanding of Hong Kong's listing regulation as a structure in evolutionary development. As such, it assumes a neutral stance on specific short-term consequences. It is premised on the proposition that a sound regulatory structure is the foundation to continued successful development of the market. This encompasses efficiency, accountability, transparency and predictability in listing regulation. While such an approach is different in nature from responses based on intuition, experience or belief, it is not intended to derogate from the potential value of those types of views.

A secondary aspect of the approach taken in this paper is that any proposed development of listing regulation should have due regard to the factors underpinning current arrangements and the ability to create sustainable pathways that facilitate future development - as opposed to a quick fix solution that may stymie proper evolution or give rise to new problems. In view of Hong Kong's position as a leading international financial centre, it is also appropriate to consider international experiences and developments, albeit in view of Hong Kong's particular characteristics.

\section{Background and evolution}

Responsibility for vetting securities offerings to the public is one of the most fundamental aspects of securities regulation. Historically, this responsibility was most commonly taken up in self-regulatory structures, of which the stock exchange has usually been the most important. Beginning with the enactment of the 1933 and 1934 securities acts in the United States in the wake of the 1929 crash, the trend has largely been towards a greater role for public regulatory agencies, with exchanges today in the majority of major financial markets limited to a role that is secondary to a primary set of requirements administered by the securities regulator of the jurisdiction. ${ }^{9}$ This evolution of responsibility has been framed in major debates at each stage, focusing invariably on the greater expertise and market understanding of self-regulatory models against the risks of conflict of interest in commercial parties' involvement in matters of regulatory interest. Over the past several decades, the argument has in general shifted toward favouring regulatory models. This has happened in tandem with the increasing commercialization and privatization of exchange services across many financial markets including North America and Europe.

\footnotetext{
${ }^{7}$ I.e. an argument that seeks to persuade and silence opposing views by virtue of the authority of the person making it. See J Locke, "An essay concerning human understanding", 1690.

${ }^{8}$ For example: the Proposal will be bad for the IPO market; the Proposal will be good for the branding and reputation of the Hong Kong IPO market.

${ }^{9}$ Such secondary roles encompass matters such as setting requirements related to the qualifying size and/or profitability of the issuer and other operational matters concerning the trading platform, clearing and settlement.
} 
In Hong Kong, this has likewise been a perennial issue of debate and the Proposal is only the most recent of a long line of attempts to determine the appropriate balance of responsibilities to support market development. As with the Gower Report in the UK in 1984, this was also an important issue in the Hay Davison Report, which set the framework underlying Hong Kong's regulatory evolution for the subsequent two decades following its release in 1988. Like the Gower Report, the Hay Davison Report came down in favour of continued market involvement: "practitioner regulation should continue but that safeguards will have to be introduced at every level."10 Accordingly, primacy in listing matters remaining with the exchange albeit with the backup of a newly established securities regulator, the SFC.

The debate returned to the fore again with the merger and listing of the SEHK, the Hong Kong Futures Exchange Limited and their clearing houses into Hong Kong Exchanges and Clearing Limited ("HKEX") in 1999. At that time, given the change in the nature of the exchange into a commercially focused listed company, arguments focused on potential conflicts of interest in listing matters as well as corporate governance matters, in particular given that HKEX itself was listed on its subsidiary, the SEHK. With strong arguments on both sides, listing matters were left with HKEX on the basis of the decision to enact a new composite regulatory framework for securities and futures, which eventually came to pass in 2003 as the SFO.

During the discussions leading to the SFO, on 1 May 2000 regulatory responsibility for companies listed on the London Stock Exchange ("LSE") was transferred from the LSE to the UK Listing Authority ("UKLA"). The UKLA was part of the now defunct Financial Services Authority and is now part of the Financial Conduct Authority ("FCA"), a move which was viewed as appropriate given the commercialization of exchange business as well as to bring UK regulation into line with EU requirements.

In the run-up to the enactment of the SFO, discussions very much centred on the proper role of the SFC vis-à-vis the HKEX and SEHK in relation to listing matters. Despite the sway of arguments in the UK, the decision was taken in the context of the SFO to proceed largely on the basis agreed at the time of the HKEX merger.

While the SFO was still under discussion (but largely final in terms of content), problems emerged in the penny stocks context, re-opening the issue. In 2003 Hong Kong appeared ready to adopt a similar regulatory model following the recommendation of a specially appointed Expert Group ${ }^{11}$ (the "Expert Group report"). This was supported by a major review by the International Monetary Fund ("IMF") likewise in the same year. However, the recommended adoption was subsequently dropped, apparently after political opposition.

In the absence of the SFC having an adequate level of oversight of listing regulation, the SMLR, introduced concurrently with the commencement of the SFO, created the dual filing regime ("DFR"). Together with the statutory provisions of the SFO addressing regulatory concerns, the DFR set the framework, which is a central subject of the current Proposal.

\footnotetext{
${ }^{10}$ Hay Davison Report, para 1.8.

${ }^{11}$ Report by the Expert Group to Review the Operation of the Securities and Futures Market Regulatory Structure, March 2003.
} 


\section{Current structure}

The qualification for and admission to listing, and the ongoing trading on a public exchange of securities once listed, is currently laid out in a relatively clear architecture in which the legislature has envisaged distinct, though closely related, roles for the SEHK and the SFC, each with independent though overlapping powers related to listing matters. The primary obligation to develop non-statutory listing requirements rests with the SEHK, subject to checks and balances in the form of meaningful powers given to the SFC as the statutory regulator for the securities industry. This includes the power to refuse proposed changes to the requirements, and to direct changes to the requirements be made.

SEHK

The SEHK, as a recognized exchange company, is subject to statutory duties to maintain an orderly, informed and fair market ${ }^{12}$ and to act in the public interest ahead of its own interests. ${ }^{13}$ It has statutory power to make non-statutory rules concerning qualification for and admission to listing ${ }^{14}$ - i.e. the Listing Rules - but that power is subject to the foregoing duties.

From an architectural standpoint, the Hay Davison framework has largely been maintained over the three decades subsequent to its release. SEHK remains the frontline regulator in relation to all listing matters and SEHK staff, under the ultimate supervision of the Listing Committee, make all day-to-day decisions in relation to the vetting of listing applications and the application of the Listing Rules to listed companies. This structure reflects the Hay Davison conclusion that market participants are the best judges of specific issues relating to listed companies and the application of the Listing Rules.

\section{SFC}

The SEHK's powers are subject to the regulatory oversight of the SFC. The SEHK must provide to the SFC explanations of the purpose and likely effect of any proposed rule, including their effect on the investing public ${ }^{15}$ (the "SEHK Reporting Obligation"), and no rule will take effect until approved by the SFC. ${ }^{16}$ The SFC can also direct the SEHK to make a rule or to amend a rule the SEHK has previously made, ${ }^{17}$ provided it has first consulted with both the Financial Secretary of the HKSAR and the SEHK. ${ }^{18}$ Should the SEHK not comply with the request, the SFC may itself make or amend the Listing Rules. ${ }^{19}$

In addition to these powers in relation to non-statutory Listing Rules, the SFC may make rules, i.e. subsidiary legislation, concerning the listing of securities. ${ }^{20}$ The SMLR that establish the dual filing regime has been made under this power. The SFC also has powers under section $36(1)(h)$ of the SFO to make subsidiary legislation on "any matter which is to be or may be prescribed by [non-statutory] rules made under section 23 [of the SFO]" (i.e. the statutory provision under

\footnotetext{
12 Section 21(1), SFO

13 Section 21(2), SFO

14 Section 23, SFO

15 Section 24(2), SFO, subject as provided in section 24(7), SFO

16 Section 24(1), SFO

17 Section 23(3), SFO

18 Section 23(4), SFO

19 Section 23(5), SFO

20 Section 36(1)(a), SFO
} 
which SEHK has made the Listing Rules). The SFC has not to date exercised its powers under this section.

The SFC also has a statutory duty under section $5(1)(b)$ of the SFO to supervise, monitor and regulate the activities carried on by SEHK. The SFC and SEHK have entered into a "Memorandum of Understanding Governing Listing Matters" ${ }^{21}$ (the "Listing MOU"), which further provides that the SFC will periodically review the SEHK's performance in its regulation of listing-related matters. ${ }^{22}$

The SFC's exercise of these powers is subject to overarching regulatory objectives, functions, powers and duties established by the SFO. ${ }^{23}$

Taken together, the SFC has considerable power over the content of the Listing Rules, including giving them a measure of statutory backing via the creation of subsidiary legislation.

\section{Prospectus authorization}

Most new listings on the SEHK involve a public offer, which invokes the prospectus law in Part II of the Companies (Winding Up and Miscellaneous Provisions) Ordinance ${ }^{24}$ ("CWUMPO"). Although the original power to authorize the prospectus rests with the SFC, ${ }^{25}$ the SFC transferred ${ }^{26}$ that power, with effect from the commencement of the SFO, ${ }^{27}$ to the SEHK where the prospectus is to be issued in connection with a listing application. ${ }^{28}$ The transfer supports the SEHK's role as the frontline regulator of listed companies although it is subject to the caveat that the SFC is to perform the functions "concurrently with" the SEHK. ${ }^{29}$ This latter provision is in keeping with the intent underlying the DFR, although the required certificate of authorization under CWUMPO is given solely by the SEHK. ${ }^{30}$

An essential component of the DFR is the SFC'S powers under the SMLR to object to or impose conditions on a listing of securities. ${ }^{31}$ The SMLR also requires ongoing disclosure materials to be provided to the $\mathrm{SFC}^{32}$ and this provides an important link to the SFC's continuing powers over the SEHK and listed issuers in relation to the suspension of dealings and cancellation of listings. ${ }^{33}$

The SEHK's statutorily defined powers and obligations to regulate the listing market are performed by or under the supervision of its Listing Committee

\footnotetext{
${ }^{21}$ Dated $28^{\text {th }}$ January 2003, this is a non-binding memorandum per Clause 3.1 (c) of the Listing MOU.

${ }^{22}$ These reviews are published on the SFC's website.

${ }^{23}$ Sections 4, 5 and 6, SFO

${ }^{24}$ Cap 32

${ }^{25}$ Sections 38(D)(3) \& (5) and 342C(3) \& (5), CWUMPO

${ }^{26}$ Under its powers to do so under section $25(1)(a)$, SFO.

${ }^{27}$ L.N. 227 of 2002

${ }^{28}$ Section 3(a), Securities and Futures (Transfer of Functions-Stock Exchange Company) Order (cap 571AE)

${ }^{29}$ Section 3(b), Securities and Futures (Transfer of Functions-Stock

Exchange Company) Order (cap 571AE) pursuant to section 25(3)(a), SFO, however, the power to grant certificates of exemption from the CWUMPO requirements has not been transferred to the SFC. Under the Proposal the SFC will no longer "routinely" issue a separate set of comments on the draft prospectus.

30 See Chapter 11A of the Listing Rules. Normal practice is that the SEHK would receive a

"no comment" letter" from the SFC before proceeding to the Listing Committee hearing

${ }^{31}$ ss. $6(2)$ and $6(3)($ b) respectively.

32 s. 7, SMLR

${ }^{33}$ SS. 8 \& 9 , SMLR
} 
("LC"), ${ }^{34}$ which is a sub-committee of the SEHK board of directors and therefore within its governance structure. The SEHK has also given an acknowledgement of the same to the SFC in the "Memorandum of Understanding Governing Listing Matters" (the "Listing MOU") executed by both parties. ${ }^{35}$ The LC itself is composed of independent individuals (practitioners in Hong Kong's financial markets) appointed jointly by the SFC and SEHK. The 28 members of the LC (except the CEO of SEHK who is ex officio at present) are chosen by the Listing Nomination Committee ("LNC"). The LNC is composed 50:50 of HKEX directors and SFC representatives. The SFC therefore also has negative control over the composition of the LC and, most importantly in the new structure, the determination of the Chairman and Deputy Chairman of the LC - i.e. the people who represent the LC on the LPC and LRC - hence the SFC's de facto control over the new sub-committees will be potentially stronger than appreciated.

This structure - path dependent and unique to Hong Kong - nonetheless seems to have addressed many of the concerns on both sides, balancing market practitioner and regulatory roles, as highlighted in a second major IMF review in 2014. Likewise, it has been sufficient to support the emergence of Hong Kong as a leading market for initial public offerings ("IPO") over most of the past decade including occupying the leading global IPO position from 2009 to 2011 and again in 2015. Size is of course only one measure of market success, and there are others, such as the quality of issuers, the types of investors attracted to the market, market turnover, the absence of market abuses, effective investor protection mechanisms, and so on.

\section{Overview of the consultation paper Proposal}

The Proposal puts forward important structural and procedural changes to Hong Kong's listing regime. While the SEHK would, at least formally, retain the listing function, an additional layer would be introduced to the regulatory structure in the form of two committees:

the LPC would "initiate, steer and decide listing policy proposals and proposed Listing Rule amendments" ${ }^{\prime 36}$ and as such would have ultimate responsibility for amendments to the SEHK's Listing Rules ${ }^{37}$ and overall listing policy; and

the LRC would "oversee, give guidance on and decide in the first instance any matter that arises in the day-to-day administration of the Listing Rules"38 which raise concerns over either suitability for listing, concern novel, potentially controversial or sensitive matters, broader policy implications, or waiver decisions that may have general effect under LR 2.04.

Both committees are to be established (in a similar manner to the Listing Committee) as sub-committees of the SEHK board - they are not committees of the SFC. ${ }^{39}$ The composition of each committee comprises an equal number of representatives from the SEHK/HKEX and the SFC including their respective committees.

\footnotetext{
${ }^{34}$ LR 2A.01

35 The Listing MOU, dated $28^{\text {th }}$ January 2003 , is a non-binding memorandum per Clause 3.1(c) of the Listing MOU. See Clause 4.6 concerning the Listing Committee.

${ }^{36}$ Para 62 of the Proposal

${ }^{37}$ Referring to the Listing Rules of both the Main Board and the Growth Enterprise Market.

38 Para 73 of the Proposal

${ }^{39}$ Committees of the SFC may be established under section 8(1), SFO.
} 
In respect of the areas for which the LPC and LRC are responsible, the Listing Committee will be retained albeit only as an advisory committee without decisionmaking powers.

The stated aims of establishing the LPC and LRC is to enable the SFC and the SEHK to work together within a collaborative setting, share perspectives, promote consensus-building and to improve accountability. These aims are set in the context of a "holistic approach" 40 of protecting the market from abusive practices in the form of manipulative practices and corporate misconduct. The question of what specific problems and issues the Proposal is seeking to address is further discussed in section 7 below.

It may be noted that while the Proposal is a consultation, the SFC nevertheless has the statutory power to impose conditions on the SEHK as the recognized exchange company. ${ }^{41}$ As the SFO does not specifically limit the conditions that may be imposed, one might consider whether the content of the Proposals could in any event be imposed as a formal condition on the SEHK. However, the SFC's power is not absolute, it is subject to the law, and it is subject to consultation requirements. Together this requires that any condition would need to be consistent with the overarching legislative intent of the SFO and other relevant provisions of Hong Kong law. The analysis in this paper suggests the arrangements contemplated by the Proposal as currently framed may not meet that standard, irrespective of whether the Proposal is sought to be implemented by way of agreement between the SEHK and the SFC, or under the SFC'S statutory powers to impose formal conditions on the SEHK.

\section{Observations}

At one level, it might appear that the Proposal does not change the basic structure of the listing regime in Hong Kong because it only concerns the composition of sub-committees of the SEHK board - decisions of the LPC and LRC technically remain decisions of the SEHK board.

Similarly, the SFC retains the ultimate power to decide listing matters by virtue of its statutory powers. While the Proposal is expressed as a streamlining of the existing regime there is nevertheless a palpable sense in which the Proposal is intended to establish new structural relationships between the SFC and the SEHK in respect of listing regulation. Per the analogy provided by the Chairman of the SFC, ${ }^{42}$ the Proposal does have the effect of moving the SFC's position from goalkeeper into the playing field and so enables the SFC to influence listing decisions at an earlier stage of the process. The two sub-committees possess some notable characteristics that effectuate a "playing field" position.

The SFC's representatives on the LPC and LRC are appointed on an ex officio basis, that is, by virtue of the office. Whoever holds the relevant office would automatically become a member of those sub-committees. Within the LPC and the LRC, representatives of both the SEHK and SFC each hold an equal vote, implying that each institution is able to exercise negative control of each subcommittee ("Negative Control"). This structure is part and parcel of the "collaborative setting" 43 of the sub-committees. The apparent equality arising upon neither party having absolute control is nevertheless subject to the looming shadow of the SFC's ultimate powers under the SFO and SMLR to direct, impose

\footnotetext{
40 Proposal, para 47

${ }^{41}$ s. $19(3)$, SFO

42 Carlson Tong, as quoted in the South China Morning Post, $3^{\text {rd }}$ July, 2016.

43 Para 19 of the Proposal
} 
or reject any matter that the LPC or LRC might recommend or approve ("Looming Control"). ${ }^{44}$

Negative Control means that the representatives of either the SFC or the HKEX can, acting together, prevent an approval of any matter. In contrast, Looming Control is possessed solely by the representatives of the SFC acting together and so implies that the SFC can compel either approval or rejection of any matter before either sub-committee. For example: for a listing application or proposed waiver the SFC wishes to reject Negative Control would be sufficient; for a proposed rule amendment the SFC insists on making Looming Control means the SFC could draw to the sub-committee's attention its ultimate statutory powers to require the SEHK to make the rule in any event.

Given the foregoing considerations, it is reasonable to query whether it is realistically possible for either sub-committee to approve or reject a matter and the SFC to hold a different view such that it would be obliged to consider its statutory functions, powers and duties. It is posited that the role of the SFC and the SEHK in Hong Kong's architecture demands an affirmative answer is capable of being given. This question shall be returned to below.

\section{Considerations}

The following sections analyze elements of the Proposal that give rise to legal and regulatory considerations. The analysis suggests the Proposal does indeed change the current arrangements, not merely through the new dynamics introduced by the LPC and LRC platforms, but by going outside what was envisaged by the legislature and by creating new conundrums that have been neither identified nor addressed in the Proposal. There are three main areas of concern: (1) regulatory architecture and legislative considerations, (2) considerations arising out of corporate law, and (3) principles of securities regulation.

\subsection{Regulatory architecture and legislative considerations}

\subsubsection{Architecture}

In support of the LPC/LRC based collaborative approach, the Proposal asserts, "To some extent, the SFC and the [SEHK] have overlapping powers and functions on listing policy-related matters." 45

That assertion represents a significant gloss on the detail of the current legislative arrangements, the architecture of which instead points to quite different roles albeit directed at commonly sought-after market objectives. Roles and objectives should not be conflated.

The SEHK Reporting Obligation mandates a channel of dialogue between two separate bodies - as each with a different role in relation to the market, each likely to bring their own perspective to market development. ${ }^{46}$ In contrast, the Proposal collapses that dynamic into single-body sub-committees that significantly diminishes the possibility of a proposer-challenger relationship

\footnotetext{
${ }^{44}$ In the context of listing applicants, it may be noted in passing that the absence of absolute control is not an impasse for certain qualification purposes under the listing rules - see HKEX Listing Decision 106-1.

45 Proposal, para 48

${ }^{46}$ Where that dialogue fails, the legislature has given the final decision to the SFC. Alternatively, as already noted, the SFC can waive the requirement in favour of the SEHK - see section 3 above.
} 
wherein two parties, at a distance, are at liberty to pursue different views in a constructive, and progressive, dialogue - this is because the SFC possesses both Negative Control and Looming Control.

The Proposal does not clarify in what ways the current arrangements operate to prevent or obstruct commonly sought-after market objectives. Whether the SEHK can under the Proposal continue to reach views independently and submit them to the SFC as contemplated by the legislature must be subject to doubt. Certainly, the market expertise of the Listing Committee would be largely disenfranchised (in relation to matters falling within the mandate of the LPC or LRC) by being relegated to an advisory role in place of its current decision making role. This may have the knock-on effect of making it more difficult to recruit suitably experienced practitioners to serve on it. Whether the presence of the SFC on the LPC and LRC, with its Negative Control and Looming Control, will operate to improve the current arrangements or merely change them, possibly affecting the existing dynamic negatively, is not known - the Proposal lacks detail in this regard.

The Proposal's description of a "simpler and more efficient" ${ }^{\prime 7}$ structure in fact actually muddies the current architecture. As detailed in the sections that follow, it gives rise to specific problems of a legal and regulatory nature that have not been identified or addressed in the Proposal.

\subsubsection{Legislative intent}

If the Proposal were implemented, certain provisions of the legislative requirements become difficult to understand and apply meaningfully, and are at risk of becoming mere formalities, or wholly irrelevant.

As already discussed, the SEHK Reporting Obligation would be at risk of becoming a paper formality. The statutory powers of the SFC to direct the SEHK to amend or make a listing rule, or to refuse, strike down or insert non-statutory listing requirements, ${ }^{48}$ are at risk of becoming meaningless where the relevant requirement has already been considered by the LPC.

The SFC'S powers under the SMLR to object to or impose conditions on listing applications are similarly neutralized where the matter has been considered by the LPC.

Together, this represents a bypassing of legislative intent. Had the legislature intended for such an intimate involvement of the SFC in the decision making subcommittees of the SEHK in respect of listing matters, it would have made provisions rather different from those that now appear in Parts II and III of the SFO. In particular, the SEHK's statutory responsibilities may have been drafted quite differently.

\subsubsection{Statutory checks and balances - SFC}

The SFC's powers to object to or impose conditions on a listing of securities ${ }^{49}$ are subject to important legislative checks and balances: (1) the power to object to a listing is limited in that it may only be exercised in specified circumstances, ${ }^{50}$ (2)

\footnotetext{
${ }^{47}$ Proposal, para 48

48 See section 3 above

49 See section 3 above

50 s. $6(2)$, SMLR
} 
it is subject to a transparency requirement, ${ }^{51}$ and (3) an exercise of either power constitutes a specified decision ${ }^{52}$ that is subject to appeal to and review by the SFAT under Part XI of the SFO.

The Proposal gives the SFC a new avenue to block a listing application via exercising Negative Control in the LRC. Since decisions of that SEHK subcommittee would not be subject to the aforesaid checks and balances, the Proposal would in effect allow the SFC to choose in which venue to exercise its will. If the SFC chose to exercise its Negative Control in the LRC to bring about a "final and conclusive" ${ }^{53}$ decision, it would not be confined by the specified circumstances, there would be no requirement for "a statement specifying the reasons for the objection", ${ }^{54}$ nor would any route of appeal to the SFAT be available.

To the extent these aspects of Hong Kong's regulatory architecture are bypassed they cease to serve their purpose and part of the system of checks and balances intended by the legislature would be lost.

At the time the DFR was introduced the SFC's power was described as a "reserve power", in line with legislative architecture, and was stated to be subject to the checks and balances generally applicable to the SFC. ${ }^{55}$ The SFC's Negative Control over the LRC (which, as well as being responsible for suitability issues and policy issues arising in connection with listing applications, will hear appeals against decisions of the Listing Committee) would appear to do away with the "reserve" nature of its blocking power.

It might be pointed out that the exercise and appeal of these powers of the SFC have never been tested, and go on to query whether these checks and balances are in fact relevant to the validity of the Proposal. ${ }^{56}$ Such a viewpoint is misguided. It is a fundamental premise of modern legal systems that where statutory power is given to a body it must be accountable in its exercise of the power, and the legitimacy of the SFC's regulatory mandate depends on this. This is articulated as an international standard in the IOSCO Principles. ${ }^{57}$ In passing it may also be noted that where listing regulation has changed to a listing authority model (such as the UKLA), a similar right of appeal from the UKLA's decisions exist - in this case to the Upper Tribunal (Tax and Chancery) ${ }^{58}$ - and that no appeals appear to have been made to date. Placing the SFC in a position of being able to exercise a public power via a path that does not provide for limits, transparency or appeal (while at the same time actively providing a pathway to

\footnotetext{
${ }^{51}$ s. 6(7), SMLR

${ }^{52}$ Items 73 and 74 of Division 1, Part 2, Schedule 8, SFO

53 Proposal, para 110

54 s. 6(7) SMLR

55 See paragraph 28 of the SFC's A Consultation Paper on the Securities and Futures (Stock Market Listing) Rules and the Securities and Futures (Transfer of Functions - Stock Exchange Company) Order, May 2002.

${ }^{56}$ Such a view might reflect the perception that an appeal is not commercially worth pursuing since, even if it is successful, the marketing and pricing of an IPO may nevertheless be prejudiced. However, there is a steady trickle of appeals against LC rejections and decisions - evidence that the commercial arguments against appeals can be overcome - and an increasing willingness in recent times to exercise rights of appeal under other regulatory mechanisms, such as against the SFC's decisions and determinations of the SFAT.

57 para 6.3

58 See the UKLA's 2014 Procedural Note 908.2 which provides for the right to appeal to the Upper Tribunal (Tax and Chancery) under the Tribunal Courts and Enforcement Act 2007.
} 
avoid such checks) would place Hong Kong significantly out of step with all major financial marketplaces.

\subsubsection{Statutory checks and balances - SEHK}

The powers of the SEHK and its duties to place the public interest ahead of its own is also subject to an important check and balance, namely, the SFC's duty to supervise, monitor and regulate the SEHK's activities. This includes the SEHK's decision making powers in relation to listing matters. That senior SFC officers would be involved in SEHK sub-committees effectively collapses the concept of a review and reporting by an independent regulator implying that the statutory duty may, in practice and to the same extent of the LPC and LRC powers, be effectively obviated by the Proposal. (See also section 6.3 .3 below regarding conflict issues.)

\subsubsection{Legislation by regulation}

That the Proposal in various ways goes outside what is contemplated by the existing regulatory architecture raises important concerns.

First there is the question of legislative intent. To the extent the Proposal is at variance with what appears to be provided by the legislature on its natural and ordinary meaning having regard to its context and purpose, ${ }^{59}$ there is a clear case for arguing that if the Proposal was implemented the SFC may be acting ultra vires the mandate the legislature has entrusted to it. The question of vires is also perhaps highlighted by the fact that the SFC has other statutory powers given to it to deal with such matters, as discussed in sections 3 and 7.4.

Second there is the risk that implementing the Proposal would amount to legislation by regulation, i.e. that regulatory powers (or status) are employed to overwrite, rewrite or reinterpret what the law provides for, or to enforce nonstatutory regulations as if they operated as laws.

Neither of the foregoing would be consistent with the conventions of administrative law or Hong Kong's position as an international financial centre.

It is suggested that, to the extent the SFC perceives defects in the regulatory oversight of listing regulation, regard should be had to its statutory duty to make recommendations on law reform ${ }^{60}$ and accordingly make them.

\subsection{Corporate law}

\subsubsection{SEHK's corporate governance}

Notwithstanding the arrangements concerning the Listing Committee, ${ }^{61}$ overall responsibility of the directors of the SEHK (including over listing matters) cannot be delegated and accordingly they retain "a residual duty to supervise or oversee the discharge of delegated functions. ${ }^{\prime 62}$ Neither the provisions in the Listing Rules nor the Listing MOU are capable of affecting this. Nor does the fact that the delegation is to the statutory regulator - this is not contemplated by the

\footnotetext{
${ }^{59}$ See HKSAR $v$ Cheung Kwun Yin (2009) 12 HKCFAR 568 and Pacific Sun Advisors Ltd and Another $v$. Securities and Futures Commission [2015] HKCFA 27.

60 s. $6(1)(p)$, SFO

${ }^{61}$ See section 3 above

62 LS Cheang and WF Wong, "Company Law: Powers and Accountability" Lexis Nexis, Hong Kong, 2003, page 606.
} 
legislation and, moreover, it has been observed that, "The appearance of undoubted integrity of a delegate does not justify abdication of overall responsibility." ${ }^{63}$ Indeed, the foregoing is reflected in the work of regulatory supervisors themselves who, when considering the role of the board in a board subject to supervision, look for clearly defined responsibilities of the board including its approach to governance of key committees of the board.

In the context of the existing regulatory architecture there is some sense for the SEHK to delegate its statutory regulatory function to a balanced and independent Listing Committee. This was envisaged as part of the fundamental reforms to the Hong Kong's securities markets following the Hay Davison Report. Under the Proposal that function is in some sense delegated back to the SFC and it is not clear what level of supervision and review the board of the SEHK could or should exercise over the senior officers of the statutory regulator that participate in its sub-committees.

\subsubsection{Shadow director}

As sub-committees of the SEHK, the LPC and LRC would exercise or control important functions of the SEHK. Unlike the Listing Committee, whose membership is diverse and its composition varying from one meeting to another, the composition of the LPC and LRC is notable in that half of the members participate ex officio, i.e. by virtue of their office, in this case their office at a single corporate body, the SFC. They are not elected as individuals but are appointed to the committees in the capacity of senior management of the SFC discharging their duties.

In view of the Negative Control and Looming Control exercisable by the SFC at those sub-committees, there is a risk that the SFC could be regarded under the Companies Ordinance as a shadow director ${ }^{64}$ of the SEHK. ${ }^{65}$ For these purposes it is noted there is no need to show the SEHK have agreed to act upon the SFC's instructions, or have surrendered their discretion, or that the SFC's influence extends to a majority of the SEHK board. ${ }^{66}$ To implement the Proposal the SEHK and the SFC would enter into an addendum to the Listing MOU. This presumably would need to provide that the SEHK board would step back from interfering in decisions of the LPC or LRC in a similar way as Clause 4.6 of the Listing MOU has done in respect of the Listing Committee. It may then be sufficient to show that the SFC's Negative Control and Looming Control amounted to the SFC being able to achieve its own purpose via these sub-committees, which would be rendered "the 'cat's paw' of the shadow director. They must be people who act on the directions or instructions of the shadow director as a matter of regular practice. ${ }^{\prime \prime 7}$ The shadow director test is an applied test not bound by any particular form and the Court has previously entertained the possibility that a person could, by virtue of their influence in committees of a board, be a shadow director. ${ }^{68}$ Certainly, it is the case, if not the clear intention of moving from goalkeeper into the playing

\footnotetext{
${ }^{63}$ Cheang and Wong, ibid.

${ }^{64}$ Section 2(1) defines shadow director as being "a person in accordance with whose directions or instructions (excluding advice given in a professional capacity) the directors, or a majority of the directors, of the body corporate are accustomed to act" .

${ }^{65}$ See also section 456(4)(b), Companies Ordinance which confirms the liability of a body corporate notwithstanding that it could not be appointed as a director of a private company that is a member of a listed group.

${ }^{66}$ See generally Cheang LS and Wong WMF, "Company Law: Powers and accountability", Lexis Nexis, Hong Kong 2003, pp.1334-1337.

${ }_{67}$ Per Harman J in Re Unisoft Group Ltd (No 2) [1994] BCC 766 at p.775

68 Moulin Global Eyecare Holdings Ltd v Lee Sin Mei Olivia [2009] 3 HKLRD. However, on the facts of that case no actual influence was found.
} 
field, that the SFC exercising its voice through the LPC and LRC will guide and control the SEHK's acts in relation to those listing matters that fall within their respective mandates. ${ }^{69}$

If the SFC were to be regarded as a shadow director it would be subject to director's duties, and to liability, including the legal possibility that it could be subject to a double derivative action. ${ }^{70}$ This would appear to be in direct conflict with its statutory duty to supervise, monitor and regulate the activities of the SEHK. While the SFC is a body that is capable of being sued, ${ }^{71}$ the creation of these sorts of potential responsibilities, liabilities and conflicts is clearly at odds with the intent of the Proposal.

It is submitted that any version of the Proposal must address and definitively rule out the shadow director issue before any implementation of it. This is not an issue of asking "who is likely to sue the SFC as a shadow director?" Rather, it is that leaving the SFC with duties owed to the SEHK (whether regarded as theoretical or not) cuts across its position as an independent regulator as intended by the legislature. Here is another point at which the Proposal would put Hong Kong significantly out of step with international practices in all major markets.

\subsection{Principles of securities regulation}

\subsubsection{Accountability}

In addition to the concerns already expressed as regards the extent to which the SFC or its officers become subject to corporate mechanisms of accountability, it would also become unclear on what basis the SFC does or should remain accountable under the statutory provisions when its senior executive officers participate in the LPC and LRC.

The legitimacy of the SFC in undertaking its regulatory mandate requires that it be subject to an appropriate framework of accountability. This is an administrative law convention and also an international standard as expressed by the IOSCO Principles, which requires the SFC to be publicly "accountable in the exercise of its functions and powers." ${ }^{\prime 72}$ It is suggested the Proposal deviates from that standard insofar as it extends the functionality of the SFC into the decision making mechanisms of another corporate body but without attendant public accountability when it exercises its powers in those sub-committees.

The earlier example given, as regards the options of the SFC to either use its powers under the SMLR to object to a listing application or to achieve the same result through Negative Control of the LRC, illustrates the issue: whereas the former is a public action subject to review by a statutory tribunal, the latter is not. This directly impacts on the accountability of the regulator in the use - or threat of use - of its powers within the sub-committees.

\footnotetext{
${ }^{69}$ One other matter falling within the mandate of the LPC may add to the shadow director risk. That is the LPC's oversight of the SEHK's Listing Department (Para 62(c) of the Proposal). The LPC would have primary responsibility for appraising senior executives of that department and the HKEX's Remuneration Committee would be required to take into account the LPC's assessment (Para 130 of the Proposal).

70 This would be the principal legal remedy for management misfeasance available to shareholders of HKEX as the parent company of the SEHK.

71 s. 3(1), SFO

72 Para 6.3
} 
An essential element of the Proposal has been described as being about "accountable decision making and transparent decision making" within an "accountable and transparent structure". ${ }^{73}$ While that may be true as between the SFC and the SEHK (i.e. on an inter-regulatory level), it remains unclear, in view of the concerns already listed, how that translates into public accountability.

The Proposal lacks detail as to how these issues would be managed in way consistent with current legislative arrangements and international best practices.

\subsubsection{Regulatory clarity}

The Proposal also introduces a measure of confusion and obscurity as regards the proper exercise of the SFC's statutory functions, powers and duties. ${ }^{74}$ The IOSCO Principles state that the capacity of a regulator to act responsibly will be assisted by "a clear definition of responsibilities, preferably set out by law."175

Under the DFR, the SFC has a statutory obligation to consider the listing application materials it receives pursuant to the SMLR. ${ }^{76}$ On the other, the SFC's ex officio members of the LRC will also be participating in formal decisions of the SEHK as regards listing applications. Might it be possible for the LRC qua SEHK to approve a listing application and the SFC to object to it?

The SFO provides that the development of listing requirements by the SEHK is subject to the approval of the SFC - again the SFO imposes a statutory obligation on the SFC to consider the submissions of the SEHK and either accept or reject them. ${ }^{77}$ Might it be possible for the LPC qua SEHK to propose a new requirement and the SFC reject it?

Must there be more than one alternative answer to the foregoing questions to maintain regulatory clarity?

To the extent that, in reality, it is not possible for the SFC to take a different position from the LRC or LPC - since otherwise this would appear to run counter to the intended benefits of the "streamlined" approach - then to that extent it must be conceded that either the SFC has in fact subsumed important statutory functions of the SEHK (see also the shadow director discussion above), or the SFC is shirking its statutory responsibilities, or both. It would not be reasonable to counter this dilemma with a suggestion that right-minded people will always think the same. It may be that the SFC officers disagree amongst themselves there is no suggestion in the Proposal they must act in concert - but there would be no transparency on that aspect of decision making, unless minutes and voting records of LPC and LRC meetings were made public, which is not part of the Proposal. In contrast, that the SFC officers are likely to vote together would not be an unreasonable assumption to make.

It would similarly be unacceptable to counter with a suggestion that the LRC is merely the means by which the SFC conveys its decision under the SMLR and that the LPC the means by which the SFC exercises its power of approval under the SFO. Such an approach may represent an abuse of legislative intent since the powers given to the SFC under the SMLR and the SFO are primarily backstop

\footnotetext{
73 SFC CEO Ashley Alder speaking at the 7th Pan Asian Regulatory Summit 9 November 2016 (the speech is available on the SFC's website) .

74 See ss. 5 \& 6, SFO

75 Para 6.2

76 S. 5 SMLR

77 s. 24(3), SFO
} 
mechanisms, not tools of coercion. It would also run afoul of problems already discussed, namely, the risk of engaging in legislation by regulation or acting ultra vires (section 6.1.3 above).

This lack of clarity in the role of the regulator also raises uncertainties as to how the SFC will be able to exercise certain powers given to it in face of potential or perceived conflicts of interest - discussed next.

\subsubsection{Conflicts}

The Proposal notes conflicts of interest as an issue under the current decisionmaking structure. It cites that the Listing Committee "members' occasional conflicts with outside professional interests and schedules prevent some from attending"78 and, notwithstanding the statutory obligation to put the interests of the public first, ${ }^{79}$ the conflicts between the commercial and regulatory roles of the HKEX. ${ }^{80}$

The Proposal does contemplate that individual staff of the SFC may need to be recused, ${ }^{81}$ though falls short of identifying whether this could arise as a result of a conflict of interest. It is suggested that the SFC need to set out more specifically the circumstances under which recusal may be necessary, and whether it considers that a conflict of interest could arise, for instance, as a result of an officer's prior involvement in an LPC or LRC decision, or because of their or their department's position of knowledge or involvement in matters being handled by the SFC. As an example, this might address whether or how reviews undertaken by the Corporate Finance division of company announcements ${ }^{82}$ that could lead to actions subsequently being taken, such as under the SFC's SMLR powers or under the Code on Takeovers and Mergers, might impact on participation in an LPC or LRC meeting concerning an issuer of possible interest.

The participation of a senior SFC officer in an LPC or LRC sub-committee may also be subject to their obligations under the secrecy provisions of section 378 of the SFO. If the officer is aware of a relevant matter subject to the secrecy requirement, then this would seem to require recusal. However, and this returns to the point made earlier as to the public or private nature of the SFC's exercise of its powers, that officer would not be prohibited from using their knowledge in the furtherance of its regulatory functions.

Unlike the breadth and depth of Listing Committee members, who originate from different organizations, the Proposal considers that any issue on the SFC's side to be specifically limited at an individual level, and accordingly that any recusal would be resolved by the appointment of another member of SFC's senior management. Given the range of powers of the SFC, including those of the Executive Director of the Corporate Finance Division of the SFC under the Code on Takeovers and Mergers, it is suggested that the situation may be more complex than expressed by the Proposal. This complexity would be amplified should an executive director of the SFC sit on these sub-committees.

Granted the SFC operates information barriers between staff (as do the financial institutions to which Listing Committee members belong). The possibility that a

\footnotetext{
78 Proposal, para 6

79 See section 3 above

80 Proposal, para 76

${ }^{81}$ Proposal, para 82

82 For the purposes of checking compliance with the Listing Rules, the Code on Takeovers and Mergers, or Part XIVA of the SFO or other laws or regulations.
} 
perceived conflict may persist - by virtue of both individuals being senior officers from the same organization - is not addressed in the Proposal. In addition to actual conflict, the perception of conflict has also been noted as an issue in the Proposal. ${ }^{83}$ Perception of conflict is an issue important to the market more generally, as noted in various codes issued by the SFC. ${ }^{84}$ This reflects the widely accepted understanding that objectivity must not only be preserved in fact but must also be perceived as being preserved. It is an important rationale behind the Listing Committee's practice that if a member's organization is involved in a matter then that member is conflicted out whether or not he or she has any actual knowledge or involvement in a relevant regard. It is unclear why a less stringent requirement should apply to the SFC, and if it did, how it could possibly operate within an organization comprised of specialized divisions.

\section{SFC independence}

Conflicts can also work in two directions, i.e. to prevent a person previously involved in a Listing Committee matter from subsequently becoming involved in a relevant regard within their own organization. One may therefore consider to what extent does the participation of a senior officer of the SFC in a meeting of an SEHK sub-committee subsequently conflict them and/or other staff of the SFC and/or the SFC itself from performing their duties as regulator?

One problem arises in relation to the SFC's statutory duty to supervise and review the activities of the SEHK. As those reviews cover the decision making process of the SEHK, it will need to address the activities of the LPC and LRC. This is a high level function of the SFC that will require its staff to review and report on activities of its own senior officers in the two SEHK sub-committees. This represents a direct conflict where subordinates of the relevant SFC officer would undertake the supervisory review. Even where that conflict is managed, the perception of institutional conflict remains, particularly as the sub-committees the subject of the review involve executive director board members of the SFC. This represents a different standard than that which is currently applied to the Listing Committee.

It is also conceivable that matters pertaining to the (dual) role of SFC officers sitting on the SEHK sub-committees may be referred to the board of the SFC and/or SFC Chairman for guidance in the ordinary course of business. This could subsequently taint or restrict the ability of the SFC board to review issues that may arise in the future from matters arising from the sub-committees.

Another kind of problem arises where senior officers of the SFC are involved in an LRC decision in relation to a particular company that subsequently becomes the subject of a regulatory investigation. It may become problematic, either in fact or perceptually, for the SFC to be capable of taking an independent or un-conflicted view when considering its powers in relation to the subject company. For example, consider where a listing application is approved at the LRC and, following the commencement of the listing, further information comes to light (whether via post listing disclosures of the issuer or otherwise) requiring a reconsideration of the situation by the SFC, such as whether to exercise powers that are unique to it and not available to the SEHK. ${ }^{85}$

\footnotetext{
${ }^{83}$ Proposal, paras $61 \& 76$

${ }^{84}$ Code on Takeovers and Mergers, rule 2.6; Code of Conduct for Persons Providing Credit Rating Services para 42(b), (c) and (e); Code on Unlisted Structured Investment Products, para 35(a)

${ }^{85}$ For example, ss. $179,182,212,213,214$ of the SFO or under ss. 8 or 9 of the SMLR.
} 
Such conflicts also give rise to other problems that extend beyond the individual concerned, for example, which other individuals in a department have been involved in internal discussions or reporting on the matter at the stage of the LRC's consideration, and so on. The more senior the SFC officer, the greater the potential problem.

The Proposal is silent on such concerns.

\section{Perspectives}

\subsection{Current communication arrangements}

The stated aims of the Proposal include enhancing cooperation and consensus building between SEHK and the SFC. Under the existing regulatory framework these parties have entered into the Listing MOU, which includes arrangements intended to address these aspects of their relationship. The Listing MOU requires the SFC and the SEHK to establish a "High Level Group" composed of senior representatives from the SFC and SEHK to review "systemic and policy issues" relating to listing matters. This High Level Group may propose amendments to the Listing Rules. At the operational level representatives of the SFC and SEHK are required to hold "Listing Matters Liaison Meetings" on a monthly basis to discuss issues arising from specific cases and more general policy issues. These two existing forums, which are loosely equivalent to the LPC and LRC, would appear to provide ample opportunity for cooperation and consensus building between the SFC and SEHK. The Proposal fails to establish why the LPC and LRC are needed to address communication issues, given the two forums for communication already in existence. This suggests the objective of establishing the LPC and LRC may well be something other than communication.

\subsection{What problem?}

The Proposal as stated is driven toward coordination, cooperation, streamlining processes and establishing clearer accountability. As already noted, certain aspects of the Proposal raise some doubt over the Proposal being capable of meeting those objectives. Conversely, the Proposal does not provide a clear case as to why it will deliver a mechanism that will solve the stated problems.

The Proposal frequently refers to streamlining processes without being specific. This is might be referring to time taken in the dialogue between the SEHK and the SFC on matters such as difficult or novel issues in new listing applications or applications for waivers. While it is appreciated there is significant commercial pressure on providing prompt responses to commercial parties, it would be helpful if the Proposal indicate in what ways this is failing at present so as to enlighten the market as to whether the Proposal, or possibly another solution within the confines of the present system, best solves the problem.

The Proposal does address an important principles-based concern: the inherent conflict of the HKEX role as a profit-oriented listed issuer with the role of its subsidiary company SEHK that regulates the market (the "SEHK Conflict"). Since decisions of the LPC and LRC remain decisions of the SEHK, the only means by which the Proposal can be said to deal with the conflict is, implicitly, that the SFC is through its participation in the two sub-committees taking a measure of control over those functionalities of the SEHK that are exposed to conflict - via Negative Control and Looming Control. Absent that proposition, it is entirely unclear on what other basis the Proposal addresses the SEHK Conflict. While adopting that proposition makes it clear, it also to some extent raises doubts over the soughtafter concept of co-operation. 
The relationship between exchange and regulator is not really a new problem at all. As far back as 1988 concern had been expressed as to the risks where the objectives in respect of the regulation of new issues and listed companies were "split haphazardly" between the SEHK and the regulatory bodies in place at that time. ${ }^{86}$ To the extent the Proposal overlays a relatively clear legislative architecture, it is submitted there is a risk that the Proposal may recreate haphazardness and, as discussed in section 6.3, unclear lines of accountability and a lack of regulatory clarity.

There also appears to be an underlying second concern that may be another driver of the Proposal: the ability of the Hong Kong regime to manage new challenges in the market, which has been widely discussed for some years. Some commentators have suggested that the Proposal is a response to ongoing differences between the SEHK and the SFC as regards market development, of which the SEHK's desire to explore the possibility of amending the Listing Rules to allow weighted voting right structures (subsequently blocked by the SFC) is an example. ${ }^{87}$ Challenges and development is of course an inherent feature of any marketplace. Concerns about the quality of new listings, and the problem of backdoor listings and shell companies to circumvent the Listing Rules have been problematic in Hong Kong at least since the $1980 \mathrm{~s} .{ }^{88}$ In the intervening three decades, the shell company problem has been tackled repeatedly and in response to new stratagems employed by commercial players. This has seen the key listing requirements remain largely unchanged while guidance notes have moved through various quantitative tests to the current combined bright line plus principles-based test. It is highly questionable whether the Proposal will in any way improve the regulatory response to this problem over and above the mechanism in place under the current architecture. Indeed, if the SFC has the solution to these market problems then it is free to suggest or impose it under the current architecture.

\subsection{Listing authority}

Some view the Proposal as a halfway step toward the listing authority model employed in the UK, citing regulation by a statutory body an approach being taken in other international markets, and there is a sense in which aspects of the Proposal imitates such a model. Developing regulatory architecture via makeshift solutions that move halfway to fully developed models does bring with it risks, as the analysis in this paper has demonstrated. Moreover, there is a clear possibility that a halfway step replete with problems may actually work to stymie proper development and lead to distractions and revisionism.

Given widespread concerns as regards a range of issues in the market, there is a strong case for a more careful and thoroughgoing review of the governance structure for listing that extends beyond the narrow ambit of the Proposal. This should include a discussion of its comparative merits and faults in light of the Expert Group report, as well as a meaningful comparison of the experiences and developments of other leading international markets. Such a review would need to take a holistic approach, and consider, for example, the particular characteristics of the Hong Kong market, what will drive it toward an international financial centre as opposed to a mainly Chinese financial centre, the mechanisms for vetting new listing applications including the regulatory oversight of sponsors

\footnotetext{
86 Davison Report, para 5.18

${ }^{87}$ I.e. following Alibaba's decision not to list in Hong Kong in 2014, the SEHK. See the SFC's statement on the SEHK's draft proposal on weighted voting rights 29 June 2015.

${ }^{88}$ Davison Report, ibid. para 5.57
} 
and the uncertainties attaching to sponsor liability, as well as enforcement options as ex post remedies where the gateway mechanism has failed or where corporate misconduct emerges. It would identify more precisely than the Proposal has done the specific issues that are perceived to be problematic. It could also bring more expressly within its scope a review of the ways in which the SEHK and HKEX have or have not been fulfilling their statutory obligations to place the interests of the investing public ahead of their own.

\subsection{SFC's extant powers}

Although under the current regulatory structure the SEHK is described as the frontline regulator of listed companies, the scope of its authority is in fact limited to approving listings and the administration of the Listing Rules. Through the SFC's regulatory oversight, the Listing Rules themselves and listing policy are ultimately subject to the approval of the SFC. Real power, in the ultimate sense, already rests with the SFC.

Except for minor breaches of the Listing Rules, enforcement against malfeasant companies and directors is almost entirely dealt with by the SFC using the extensive powers granted to it under Division 2 of Part $X$ of the SFO, through which the SFC has had a number of significant enforcement successes in recent years.

Some commentators have suggested that the SFC should use its existing powers to ramp up enforcement actions against issuers. However, enforcement is no substitute for a quality gateway mechanism. While some improvements in the gateway mechanism were made via the sponsor regime in 2013, further development in prospectus law and sponsor regulation remains desirable in the interests of fostering market integrity. As already noted, a more holistic view of market development needs to be adopted that extends beyond the operations of the DFR, and this too is within the SFC's extant powers, and responsibilities, to consider.

The Proposal seems to be motivated by a desire for the SFC to be more involved at an early stage of and have more control over the listing process, with a view to pre-empting problems. However, it remains unstated in the Proposal why the SFC through the LPC and LRC would fare any better in this regard than under the current arrangements. The danger is that by merging the SFC into the regulatory decision making process it will, as discussed in section 6 , create new problems between the SFC's listing policy and approval role and its important role as a post-listing enforcer.

If specific problems are more clearly identified, specific solutions can be devised. For example, waivers of Listing Rules are frequently mentioned as a source of problematic issues and LR 2.04 is a specific concern of the LRC's mandate. ${ }^{89}$ It would be well within the existing power of the SFC to require the cooperation of the SEHK to seek the SFC's approval in respect of waivers, either via an understanding, an amendment to the Listing MOU or by way of its powers under sections 23(3) or 36(1) of the SFO - any of these approaches would be specific and target an alleged problem that would not encounter more general problems in its validity within the existing regulatory architecture.

${ }^{89}$ Para $73(d)$ of the Proposal 


\section{Conclusions}

While legislative change is by no means easy in Hong Kong's current political environment, and this may encourage regulators in Hong Kong to pursue alternative approaches, this is an area of fundamental importance to Hong Kong's present and future success as an international financial centre and therefore merits the most careful consideration.

There is nothing contentious in asserting that the development of the regulatory framework should not be frozen in time but should evolve so as to remain fit for purpose in view of current and emergent market conditions. Indeed, Hong Kong's regulatory architecture has evolved in significant ways since the Hay Davison Report and the establishment of the SFC in 1989. Many of these developments have been in response to the changing profile of the Hong Kong market, including its internationalization, its overall size in global terms, and Hong Kong's special position in relation to the rapid emergence of Chinese business enterprises since the early 1990s. This has resulted in some principles being tested against practices in other markets (such as the one share one vote principle and weighted voting rights) while others have been reinforced by both established and developing international standards (such as the nature and scope of the regulatory mandate). Identifying which aspects of Hong Kong's architecture comprise essential foundations of the system and which are in need of modernization is not a straightforward matter. Any development must of course occur within the wider framework of Hong Kong's legal system, and it will be noted that this paper has identified aspects of the Proposal that are questionable in this regard.

Can the Proposal work as a pragmatic interim measure? Given the concerns identified in this paper, if the Proposal is to be pursued, it must be recognized that its fit within the current legislative architecture is problematic. Both the form of the Proposal (the use of SEHK board sub-committees) and the substance of the Proposal (the effective controls given to the SFC outside the regulatory architecture) give rise to significant issues that require further consideration. It remains unclear why that approach has been proposed, skirting as it does legislative intent, when the SFC already has wide powers in relation to listing requirements given to it by the legislature that it could seek to use to achieve the objective of inserting itself into an earlier stage of listing regulation. If it were to use those powers, the SFC would remain squarely within the confines of legislative intent and avoid many of the problems identified in this analysis. Such problems are troubling when considered in light of the foundations of the SFC as an independent regulator with extensive reserve powers to intervene where the exchanges fall down on the job. As such, there is a risk that the Proposal could work to stultify listing regulation development and/or send it backwards.

Hong Kong, as a member of IOSCO, has endorsed its commitment to the IOSCO Principles and has indicated it intends to use best endeavours to ensure adherence to the principles. ${ }^{90}$ Some of the problems enumerated in this paper invoke elements of the IOSCO Principles, insofar as listing regulation is concerned: that the powers of the SFC should remain "clear and objectively stated" and that it continues to possess "the capacity to perform its functions and exercise its powers." ${ }^{\prime 1}$

The primary conclusion of this paper is that implementation of the Proposal would create dangerous legal and regulatory conundrums within what is currently a

\footnotetext{
90 Per IOSCO Resolution No. 41, September 1998. See IOSCO Principles, p.3.

${ }^{91}$ IOSCO Principles, para 6.1
} 
relatively clear architecture, while at the same being unclear as to why the LPC and LRC would bring any benefits over and above the current arrangements. The Proposal in its present form would not be a positive development, unless and until such issues are properly resolved. Failing to do so may cause the SFC's continued standing as an independent regulator acting intra vires in relation to listing regulation to be called into question. Such an outcome would be profoundly undesirable.

It is suggested that a more holistic view of market development needs to be adopted that extends beyond the decision making mechanisms of the dual filing regime and identifies more precisely the specific issues that are problematic. Doing so would permit more targeted and sustainable oversight mechanisms to be developed. 